\title{
KOLEKSI TUMBUHAN TERANCAM DI KEBUN RAYA CIBODAS DARI HASIL EKSPLORASI TAHUN 2015-2017 DI BENGKULU DAN LAMPUNG (SUMATRA)
}

\author{
Dwinda Mariska Putri, Yudi Suhendri \\ Balai Konservasi Tumbuhan Kebun Raya Cibodas - LIPI \\ email: dwinda.mariska@gmail.com
}

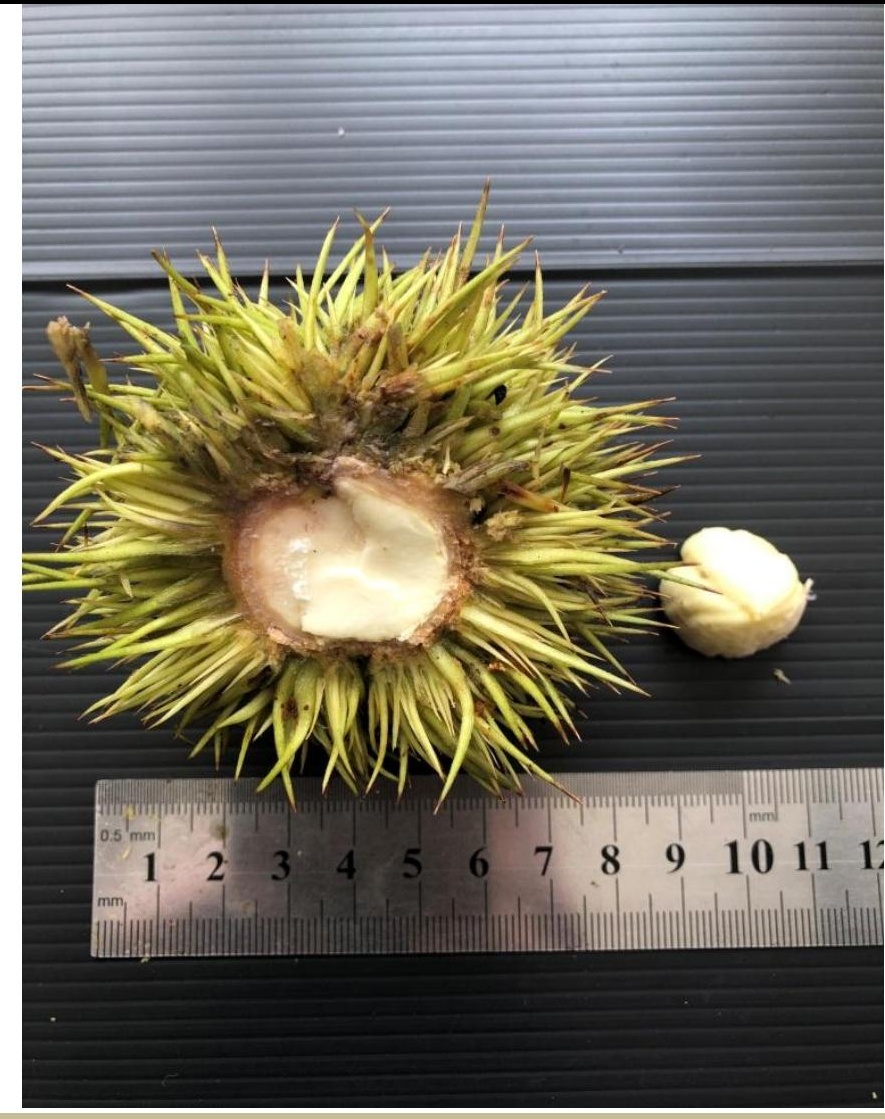

\section{ABSTRACT}

Irisan buah Castanopsis tungurrut

The living collection of Indonesian Botanic Gardens mainly derived from its native habitat accross Indonesian Archipelago. Over the years, native western Indonesian flora have been cultivated in Cibodas Botanic Gardens, a mountaineous site for plant from higher altitude of origin. During 2015-2017 flora exploration program were focused in 3 conservation areas in two province of Sumatra Bengkulu and Lampung. Each site is Gunung Seblat National Park and Bukit Raje Mandare surround Gunung Patah in Bengkulu, other is Tanggamus protected forest in Lampung. There are 2 threatened plants listed in IUCN red list coming from this exploration namely Castanopsis tungurut (Blume) A.DC and Lithocarpus indutus (Bl) Rehd.

\section{PENDAHULUAN}

Kebun Raya Cibodas (KRC) memiliki tugas melakukan inventarisasi, eksplorasi, koleksi, penanaman, dan pemeliharaan tumbuhan terutama tumbuhan dataran tinggi. KRC melaksanakan tugas tersebut terutama terhadap jenis-jenis tumbuhan terancam. Jenis-jenis terancam punah Indonesia terus bertambah karena penebangan liar, kerusakan habitat, serta pengambilan berlebih di alam. Untuk itu KRC tidak hanya merawat koleksi namun juga menambah koleksi tumbuhan khususnya tumbuhan yang terancam punah melalui kegiatan eksplorasi (Normasiwi et. al., 2015).

KRC memiliki tugas untuk melakukan eksplorasi dan konservasi tumbuhan dataran tinggi basah bagian barat Indonesia. Kawasan yang menjadi fokus kegiatan eksplorasi adalah dataran tinggi basah termasuk di antaranya Pulau Jawa dan Pulau Sumatera (Surya et al., 2013). Penentuan area eksplorasi umumnya adalah daerah yang belum banyak diketahui keanekaragaman hayatinya serta dilaporkan merupakan habitat dari jenis terancam punah. 
Eksplorasi merupakan usaha untuk menambah koleksi dengan mengambil spesimen di alam. Kegiatan ekplorasi memiliki tujuan untuk mendokumentasikan keanekaragaman flora dataran tinggi basah serta mengumpulkan spesimen hidup maupun herbarium sebagai pengkayaan koleksi Kebun Raya Cibodas (KRC) (Normasiwi et al., 2015).

Berdasarkan Peraturan LIPI No. 4 2019, LN 2019/NO. 40, 22 HLM, spesimen yang dikoleksi berupa anakan, biji, setek dan/atau material lain suatu jenis tumbuhan. Spesimen setek, biji, dan tunas yang telah dikoleksi kemudian akan diaklimatisasi dengan kondisi KRC menggunakan medium yang telah dikembangkan. Saat spesimen tumbuh dengan baik, spesimen kemudian dipindahkan menjadi koleksi tumbuhan KRC. Material lain yang dikoleksi adalah spesimen herbarium. Spesimen herbarium merupakan rekaman data jenis tersebut pernah ditemukan dan dikoleksi.

Prioritas utama kegiatan eksplorasi flora adalah mengkoleksi flora endemik, berpotensi sebagai bahan pangan, tumbuhan hias, tumbuhan obat dan lainlain. Jenis lain yang dikoleksi adalah flora terancam kepunahan dan habitatnya mulai terdegradasi. Kegiatan eksplorasi dan penelitian diharapkan dapat berkontribusi terhadap pelestarian flora dataran tinggi basah Indonesia bagian barat. Hasil kegiatan akan dikonservasi secara ekssitu, menjadi bahan penelitian, pendidikan lingkungan, dan ekowisata (Noviady et al., 2017).

Lokasi yang dipilih sebagai lokasi eksplorasi adalah lokasi dengan kemiripan iklim dengan $\mathrm{KRC}$, yaitu dataran tinggi yang memiliki iklim basah, serta belum pernah dilakukan eksplorasi sebelumnya.
Lokasi yang dijadikan prioritas utama eksplorasi oleh KRC adalah Indonesia bagian barat. Sejak tahun 2015 hingga 2017 eksplorasi dipusatkan di pulau Sumatra. Pada tahun 2015 eksplorasi dilakukan di Gunung Seblat, provinsi Bengkulu. Pada tahun 2016 eksplorasi dilakukan di Gunung Patah, provinsi Bengkulu. Eksplorasi tahun 2017 dilakukan di Gunung Tanggamus, provinsi Lampung.

\section{EKSPLORASI GUNUNG SEBLAT}

Pada tahun 2015, eksplorasi dilakukan di Gunung Seblat, provinsi Bengkulu, Sumatra. Gunung Seblat berada di dalam area Taman Nasional Kerinci Seblat (TNKS). Ekosistem TNKS berupa dataran tinggi dengan kondisi hutan alami sehingga keanekaragaman tumbuhan tinggi. TNKS merupakan taman nasional terbesar di pulau Sumatra. Ancaman terbesar terhadap ekosistem TNKS adalah penggunaan lahan yang berbatasan dengan taman nasional (Noviady et al., 2017).

Spesimen hidup yang didapatkan dari hasil eksplorasi di Gunung Seblat sebanyak 371. Dari jumlah tersebut, sebanyak 76 spesimen berhasil dijadikan koleksi kebun (Tabel 1). Spesies terancam yang didapatkan dari eksplorasi tersebut sebanyak satu jenis, yaitu $C$. tungurrut. Status keterancaman berdasarkan IUCN Red List adalah Endangered. Castanopsis tungurrut menjadi terancam di alam disebabkan oleh alih fungsi lahan. Hutan alami jenis ini ditemukan telah diubah menjadi lahan untuk monokultur. Selain itu, jenis ini dimanfaatkan untuk diambil kayunya dengan cara illegal tanpa mengindahkan kelestariannya di alam. Biji dari C. tungurrut dapat dimakan dan memiliki rasa yang khas. 
Tabel 1. Hasil eksplorasi tumbuhan di Bengkulu dan Lampung tahun 2015-2017

\begin{tabular}{|l|c|c|c|c|c|c|c|}
\hline \multicolumn{1}{|c|}{ Lokasi } & Tahun & Hasil & Koleksi & $\begin{array}{c}\text { \% (Koleksi } \\
\text { /hasil } \\
\text { eksplorasi) }\end{array}$ & $\begin{array}{c}\text { Jumlah } \\
\text { Jenis } \\
\text { terancam }\end{array}$ & $\begin{array}{c}\text { Kategori } \\
\text { keterancaman }\end{array}$ & $\begin{array}{c}\text { Jenis } \\
\text { terancam }\end{array}$ \\
\hline Gunung Seblat & 2015 & 371 & 76 & 20.49 & 1 & EN & C.tungurrut \\
\hline Gunung Patah & 2016 & 352 & 54 & 15.34 & 1 & VU & L. indutus \\
\hline $\begin{array}{l}\text { Gunung } \\
\text { Tanggamus }\end{array}$ & 2017 & 723 & 85 & 11.76 & - & - & - \\
\hline
\end{tabular}

Castanopsis tungurrut (Blume) A.DC. memiliki sinonim Castanea tungurrut $\mathrm{Bl}$. dan C. conspersispina Merr (Backer et Bakh. v.d. Brink, 1965). Nama daerah jenis ini dalam Bahasa Sunda adalah Tunggereuk (Damayanti \& Rulliaty, 2010). Jenis ini memiliki persebaran di Peninsular Malaysia, Sumatra serta Jawa. Castanopsis tungurrut dapat tumbuh hingga $20 \mathrm{~m}$, daun berambut cokelat keemasan ketika muda, daun tua berwarna hijau tua di permukaan atas (Gambar 1B) kecokelatan di bagian bawah (Gambar 1C). Bunga inflorescence terminal dalam grup 2 atau 3 , buah sudut tiga, cokelat muda, tertutup kulit keras berduri berwarna hijau muda (Gambar 1F), satu biji dalam satu cupule (Whitmore, 1972). C. tungurrut dilaporkan ditemukan dalam rentang ketinggian 1000-1500 mdpl. C. tungurrut memiliki kayu keras yang dapat dimanfaatkan sebagai bahan bangunan. Faktor penyebab kepunahan jenis ini adalah alih fungsi lahan, semula hutan hujan tropis menjadi permukiman (Barstow \& Kartawinata, 2018). Pemanfaatan sebagai pangan belum dimanfaatkan secara luas. Jenis ini hanya dipanen liar di alam sehingga memiliki nilai ekonomi rendah sebagai bahan pangan (Milow et al., 2014).

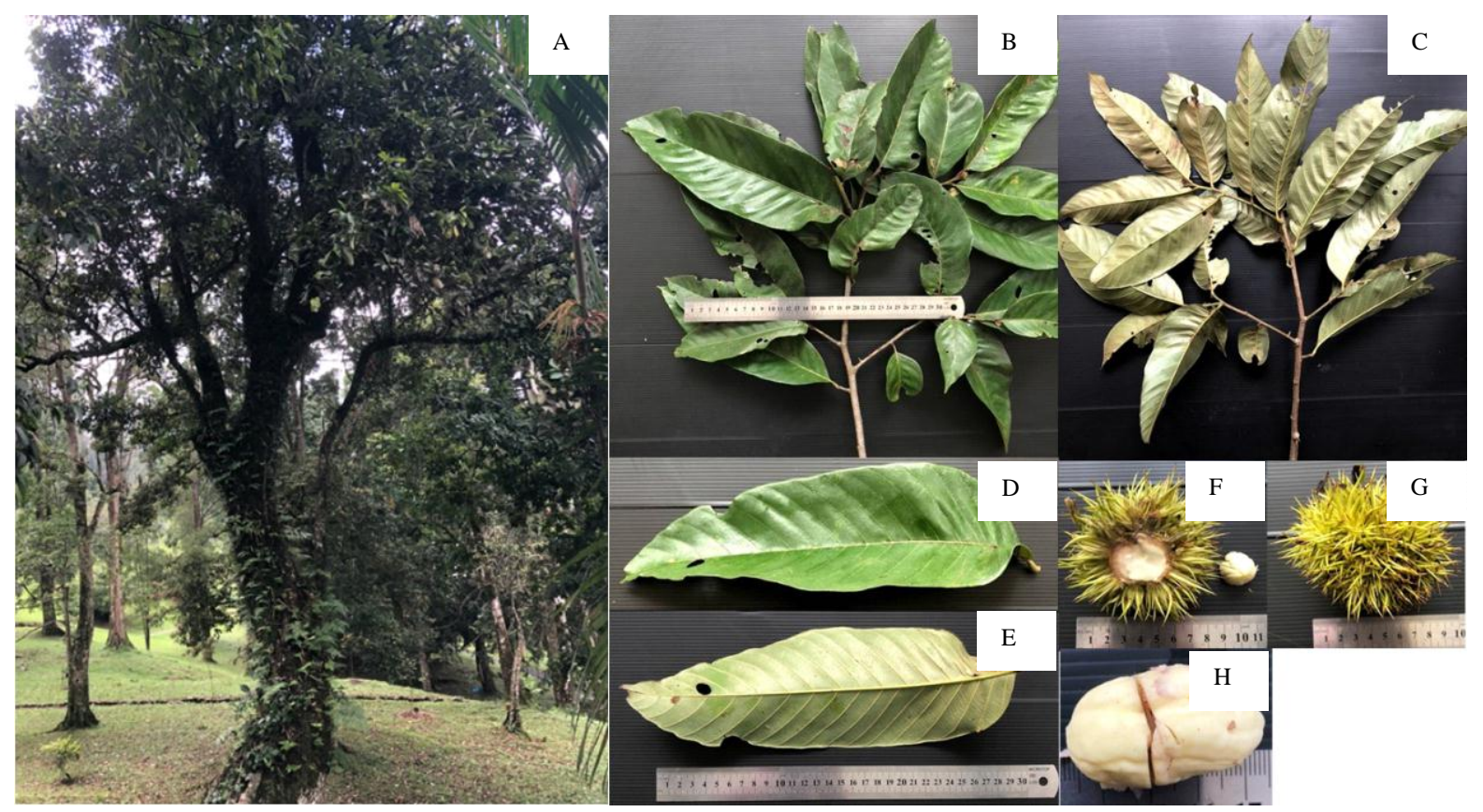

Gambar 1. Castanopsis tungurrut (Blume) A.DC. (A) perawakan pohon, (B) tampak permukaan cabang, (C) tampak bawah cabang, (D) tampak adaxial daun, (E) tampak abaxial daun, $(F)$ irisan buah, $(G)$ tampak buah $C$. tungurrut, dan (H) biji dengan kulit dalam setelah dibersihkan 


\section{EKSPLORASI GUNUNG PATAH}

Pada tahun 2016, eksplorasi dilakukan di Gunung Patah, provinsi Bengkulu, Sumatra. Eksplorasi dilakukan di kawasan Hutan Lindung Bukit Raje Mandare. Hutan Lindung Bukit Raje Mandare memiliki iklim yang sama dengan $\mathrm{KRC}$, yaitu dataran tinggi basah. Kawasan tersebut memiliki jenis tumbuhan yang beragam sehingga dipilihs sebagai lokasi eksplorasi. Namun demikian, hutan lindung tersebut terancam oleh alih fungsi lahan terutama kopi dan sawit (Muhaimin et al., 2016).

Total spesimen yang didapatkan dari eksplorasi tersebut adalah 352 spesimen hidup. Jumlah spesimen yang dijadikan koleksi sebanyak 54 jenis. Spesies terancam yang didapatkan dari hasil eksplorasi tersebut adalah satu jenis, yaitu L. indutus. Berdasarkan kategori IUCN Red List, jenis tersebut berada dalam status keterancaman vulnerable berdasarkan asesmen tahun 1998. Faktor utama keterancaman $L$. indutus adalah alih fungsi habitat alaminya (World Conservation Monitoring Centre, 1998).
Lithocarpus indutus (BI.) Rehd. Sinonim: Quercus induta Bl. (Backer et Bakh. v.d. Brink, 1965). Nama daerah: pasang bodas, pasang batu (Sunda). Lithocarpus indutus ditemukan hidup pada kisaran ketinggian1000-1500 mdpl. Jenis ini dilaporkan terdistribusi di pulau Jawa (Soepadmo, 1972). Lithocarpus indutus termasuk dalam kategori rawan berdasarkan asesmen tahun 1998. Dalam penelitian di TNGGP pada tahun 2004 menunjukkan penurunan jumlah individu L. indutus sebesar $75 \%$ (Wihermanto, 2004). Pola persebaran jenis ini adalah mengelompok. Agen dispersal umum untuk marga Fagaceae adalah mamalia kecil seperti Rodensia (Yang et al., 2015). Ciri-ciri morfologi $L$. indutus adalah memiliki daun majemuk, berbentuk elipsoblong-lanset, daun muda memiliki tangkai berbulu kecokelatan, permukaan daun berbulu, daun tua memiliki warna adaxial hijau tua dan warna abaxial abu-abu kecokelatan dengan bulu tipis (Gambar 2B,C,D,E). Cupule keras, terdapat 1-4 biji, berbentuk cangkir yang lebar, dengan dasar obconical (Gambar 2F,G).

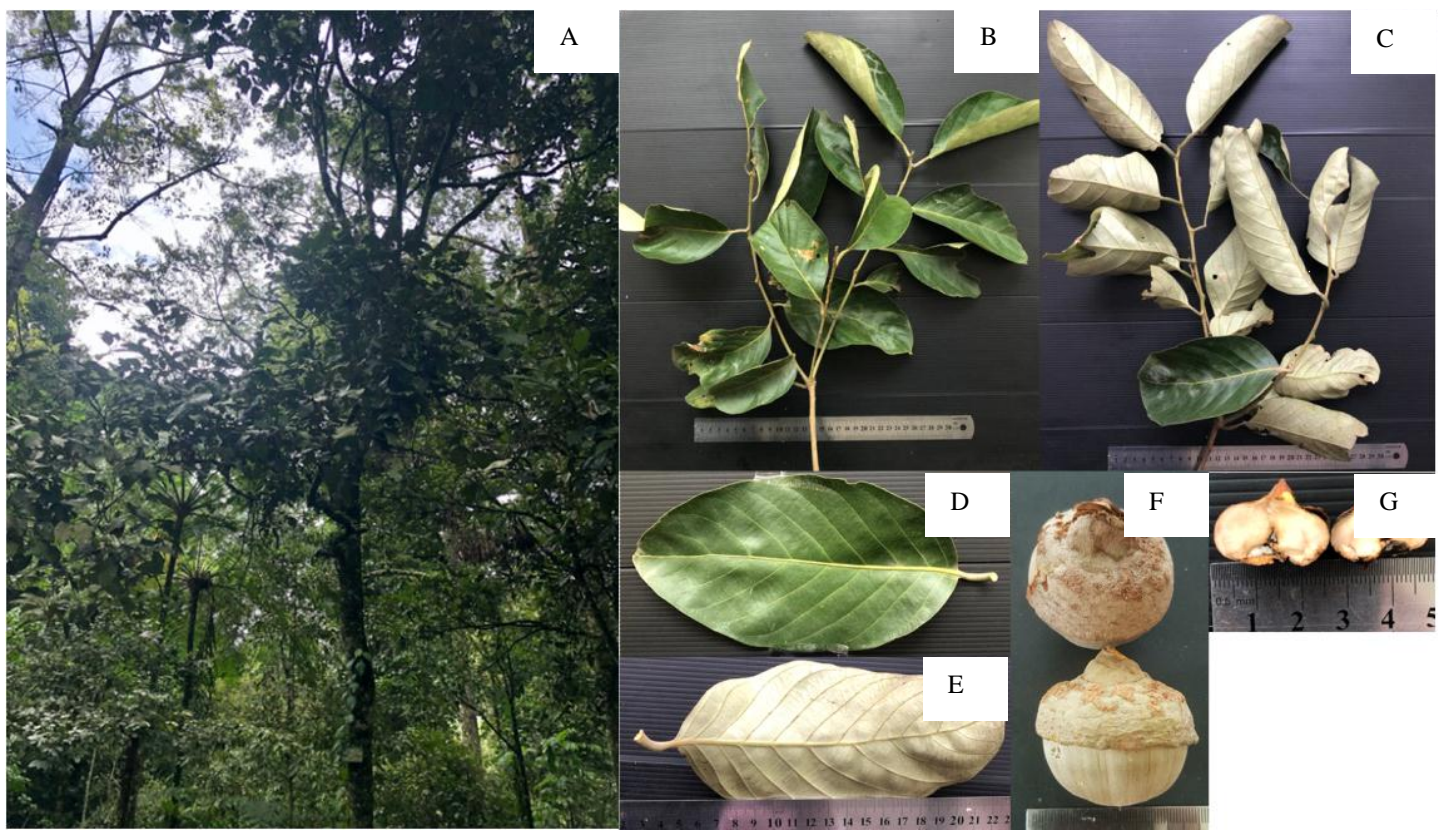

Gambar 2. Lithocarpus indutus (BI.) Rehd. (A) perawakan pohon, (B) tampak permukaan cabang, (C) tampak bawah cabang, (D) tampak adaxial daun, (E) tampak abaxial daun, $(F)$ buah utuh, dan $(G)$ irisan biji 


\section{EKSPLORASI GUNUNG TANGGAMUS}

Pada tahun 2017, eksplorasi dilakukan di kawasan Hutan Lindung Gunung Tanggamus,provinsi Lampung. Wilayah ini dipilih karena masih memiliki vegetasi beragam dan masih sedikit informasi mengenai vegetasi di wilayah tersebut. Lokasi eksplorasi dilakukan di kawasan Hutan Lindung yang ada dalam pengelolaan Kesatuan Pengelolaan Hutan Lindung (KPHL) Kota Agung Utara. Dari eksplorasi di kawasan Hutan Lindung Gunung Tanggamus didapatkan sejumlah 723 spesimen. Sebanyak 85 spesimen dijadikan koleksi tumbuhan KRC. Pada eksplorasi tersebut tidak didapatkan jenis tumbuhan terancam yang terdaftar di dalam IUCN Red List. Namun demikian, total koleksi spesimen yang didapatkan merupakan terbanyak dari dua eksplorasi sebelumnya.

\section{PENUTUP}

Kebun Raya Cibodas melakukan eksplorasi untuk menambah koleksi tumbuhan. Tumbuhan yang dikoleksi terutama tumbuhan dilindungi, tumbuhan endemik dan memiliki nilai ekonomi. Eksplorasi tahun 2015-2017 dilakukan di dua provinsi, yaitu Bengkulu dan Lampung. Sebanyak dua jenis terancam punah berhasil dikoleksi dari eksplorasi di tahun tersebut, yaitu Castanopsis tungurrut (Blume) A.DC dengan status keterancaman berdasarkan IUCN Red List adalah endangered dan Lithocarpus indutus (BI.) Rehd. dengan status keterancaman vulnerable. Castanopsis tungurrut dikoleksi dari Taman Nasional Gunung Seblat, Bengkulu. Lithocarpus indutus dikoleksi di Hutan Lindung Bukit Raje Mandare, Gunung Patah, Bengkulu. Tidak ada jenis terancam punah yang dikoleksi dari eksplorasi di kawasan Hutan Lindung Gunung Tanggamus Lampung, namun spesimen koleksi yang didapatkan merupakan terbanyak dari dua eksplorasi sebelumnya.

\section{DAFTAR PUSTAKA}

Barstow, M., \& K. Kartawinata. 2018. Castanopsis tungurrut. The IUCN Red List of threatened species 2018: e.T62004621A62004623. https://dx.doi.org/10.2305/IUCN.U K.2018-

1.RLTS.T62004621A62004623.en . Diakses tanggal 09 Maret 2020.

Damayanti, R., \& Rulliaty, S. 2010. Anatomical properties and fiber quality of five potential commercial wood species from Cianjur, West Java. Journal of Forestry Research, 7: 53-69.

Milow, P., Malek, S.B., Edo J., \& Ong, H. 2014. Malaysian species of plants with edible fruits or seeds and their valuation. International Journal of Fruit Science, 14: 1-27. https://doi.org/10.1080/15538362. 2013.801698

Muhaimin, M., Hidayat, I.W., \& Muslim. 2016. Eksplorasi tumbuhan dan studi komposisi vegetasi di zona bukit dari Gunung Patah, Bengkulu. Prosiding Seminar Nasional Masyarakat Biodiversitas Indonesia, 2: 132-137. https://doi.org/10.13057/psnmbi/m 020202

Normasiwi, S., Mutaqien, Z., Noviady, I., Susanto, E., \& Ashari, A.J. 2015. Eksplorasi flora di kawasan hutan lindung Gunung Talamau, Sumatera Barat dan hutan lindung Gunung Sibuatan, Sumatera Utara untuk pengayaan koleksi Kebun Raya Cibodas. Prosiding Seminar Nasional Masyarakat Biodiversitas Indonesia, 
1: 501-508. https://doi.org/10.13057/psnmbi/m 010321

Noviady, I., Hidayat, I.W., \& Nurlaeni, Y. 2017. Komposisi vegetasi dasar di hutan Bukit Seblat yang berbatasan dengan Desa Seblat Ulu, Taman Nasional Kerinci Seblat, Sumatera. Prosiding Seminar Nasional Masyarakat Biodiversitas Indonesia, 3: 461465.

https://doi.org/10.13057/psnmbi/m 030327

Surya, M.I., Lailati, M., Ekasari, I., Nurlaeni, Y., Astutik, S., Normasiwi, S., Gumilang, A.R., Junaedi, D.I., Mutaqien, Z., Nurdiana, D.R., Rahman, W., Destri, \& Rozak, A.H. 2013. Konservasi tumbuhan di Kebun Raya Cibodas sebagai penyelamat keanekaragaman hayati pegunungan Indonesia. Lokakarya Nasional "Keanekaragaman Hayati Sebagai
Modal Dasar Pembangunan". Bogor.

Soepadmo, E. 1972. Fagaceae. Flora Malesiana Ser. I. 7: 265-403.

Wihermanto. 2004. Dispersi asosiasi dan status populasi tumbuhan terancam punah di zona submontana dan montana Taman Nasional Gunung GedePangrango. Biodiversitas, 5: 1722.

https://doi.org/10.13057/biodiv/d05 0104

Yang, Y., Huang, L., Qian, S., \& Fukuda, S. 2015. Completing the life history of Castanopsis fargesii: changes in the seed dispersal, seedling and sapling recruitment patterns. European Journal of Forest Research, 134: 11431154.

https://doi.org/10.1007/s10342015-0916-9 